\title{
Estilos de uso e significados dos autorretratos no Instagram: Identidades narrativas de adultos jovens brasileiros
}

\section{Styles of use and meanings of self-portraits on Instagram: Narratives identities of young Brazilian adults}

\author{
Estilos de uso y significados de los autorretratos en el \\ Instagram: Identidades narrativas de jóvenes adultos \\ brasileños
}

\author{
Zakiee Castro Mufarrej Hage* \\ Pontifícia Universidade Católica de São Paulo, São Paulo, São Paulo, Brasil
}

Ida Kublikowski**

Pontifícia Universidade Católica de São Paulo, São Paulo, São Paulo, Brasil

\begin{abstract}
RESUMO
O Brasil é o segundo país que mais acessa o Instagram e seu público mais conectado são os adultos jovens. Com foco na constituição de identidades narrativas e de uma perspectiva sistêmica, a presente pesquisa buscou identificar quantitativamente os estilos de uso e compreender qualitativamente os significados atribuídos por jovens adultos aos autorretratos postados no Instagram. Foi adotado o método misto sequencial explanatório. Primeiramente, foram contabilizadas e analisadas imagens postadas durante dez dias por 30 homens e 30 mulheres brasileiros, com idades entre 25 e 29 anos. Na fase seguinte, foram entrevistados seis colaboradores, três homens e três mulheres, selecionados a partir da quantidade de fotos postadas no período abordado. A análise estatística evidenciou que a categoria de imagens mais postada por homens e mulheres corresponde à dos autorretratos. A análise temática das entrevistas indicou que o Instagram oferece maior liberdade de exposição e que os participantes sofrem influência do olhar externo. Os significados atribuídos às postagens foram: privacidade, memória, beleza e felicidade. Identidades narrativas imagéticas se constituem e moldam as formas de expressão possíveis na rede, regidas pelos ideais de gênero, beleza e felicidade. A liberdade imaginada nas escolhas biográficas se vê tolhida por um olhar que vigia e curte.
\end{abstract}

Palavras-chave: Instagram, redes sociais, autorretratos, jovens.

\section{ABSTRACT}

Brazil is the second country that most accesses Instagram and its most connected public are the young adults. Focusing on the constitution of narrative identities and from a systemic perspective, the present research sought to quantitatively identify the styles of use and to understand, 
qualitatively, the meanings attributed by young adults to self - portraits posted on Instagram. The mixed sequential explanatory method was adopted. First, we analyzed the images posted for 10 days by 30 Brazilian men and 30 women, aged 25-29. In the next phase, six contributors, three men and three women were interviewed, selected from the number of photos posted in the covered period. Statistical analysis showed that the category of images most posted by men and women corresponds to the selfportraits. The thematic analysis of the interviews indicated that the Instagram offers greater freedom of exposure and that the participants are influenced by an outside view. The attributed meanings to the posts were: privacy, memory, beauty and happiness. Narrative identities are shaped in a way to constitute the possible forms of expression in the network, governed by ideals of gender, beauty and happiness. Eyes that watch and "like" hampers the freedom of the biographical choices.

Keywords: Instagram, social networks, self-portraits, young adults.

\section{RESUMEN}

Brasil es el segundo país que más accede al Instagram y su público más conectado son los adultos jóvenes. Mirando la constitución de identidades narrativas y de una perspectiva sistémica, la presente investigación buscó identificar cuantitativamente los estilos de uso y comprender, cualitativamente, los significados atribuidos por jóvenes adultos a los autorretratos publicados en el Instagram. Se adoptó el método mixto secuencial explicativo. En primer lugar se contabilizó y analizó imágenes publicadas durante diez días por 30 hombres y 30 mujeres brasileños, con edades entre 25 y 29 años. A continuación, se entrevistó tres hombres y tres mujeres, seleccionados a partir de la cantidad de fotos publicadas en el período. El análisis estadístico evidenció que la categoría de imágenes más publicada por hombres y mujeres corresponde a los autorretratos. El análisis temático de las entrevistas indicó que el Instagram ofrece mayor libertad de exposición y que los participantes sufren influencia de la mirada externa. Los significados atribuidos a las publicaciones fueron: privacidad, memoria, belleza y felicidad. Las identidades narrativas se constituyen y moldean las formas de expresión posibles en la red, regidas por los ideales de género, belleza y felicidad. La libertad imaginada en las elecciones biográficas se ve restringida por una mirada que vigila y "me gusta".

Palabras-clave: Instagram, redes sociales, autorretratos, jóvenes adultos.

\section{As Redes Sociais na Atualidade: O Instagram}

Os jovens nascidos na década de 1990 cresceram envolvidos por inovações tecnológicas e imersos no universo virtual, sendo a experiência com as tecnologias parte integrante de suas vivências pessoais e profissionais. Atualmente, o cenário virtual permite de forma acessível e ampliada a exposição dos sujeitos e a espetacularização do cotidiano.

A pesquisa TIC Domicílios (2017), de responsabilidade do Comitê Gestor de Internet no Brasil, investigou quais os hábitos dos brasileiros no uso da Internet. As atividades mais frequentes são: mandar mensagens pelo WhatsApp, Skype ou chat do Facebook 
$(90 \%)$, seguidas pelo uso de redes sociais como Facebook ou Instagram (71\%).

O Instagram surgiu em 2010 e atualmente ultrapassa 400 milhões de usuários ao redor do mundo, que compartilham mais de 80 milhões de fotos por dia, segundo dados do próprio aplicativo (Instagram, 2016). Em pesquisa realizada com cerca de 1.000 jovens brasileiros entre 18 e 35 anos, foi concluído que $61 \%$ acessam pelo menos uma vez por dia o aplicativo (Tozetto, 2015).

Apesar da quantidade extensa de usuários, observamos a ausência de estudos no Brasil, especialmente na área da Psicologia, que contemplem o Instagram. Assim, lançar luz sobre os estilos de uso e significados das experiências on-line, em meio a um cenário no qual, além das modificações nas noções de tempo e espaço e de público e privado, as pessoas expõem seus cotidianos, constantemente reconfigurados de forma idealizada, nos conduz à relevância do presente estudo, que oferece subsídios para lidar, nas práticas clínicas, com o impacto produzido por essa exposição que cria universos e subjetividades, entregues ao mundo na forma de significados (Sibila, 2008).

No contexto das redes, as múltiplas vozes que direcionam estilos de vida que os indivíduos devem seguir se misturam à voz do próprio sujeito sobre aquilo que ele considera melhor para si (Gergen, 1992), com imagens manipuladas para mostrar as suas melhores versões (Hogan \& Wellman, 2014). A identidade se relaciona à concepção de como me percebo a partir do que percebo que os outros percebem de mim. Uma aproximação narrativa ao conceito nos remete à ideia de uma pessoa que se modifica ao designar-se a si mesma por meio das histórias que conta sobre si e que a constituem. Tais histórias, expressas em linguagem, são compreendidas em significações (Ricoeur, 1997).

Nesse sentido, a criação de um senso coerente de identidade pressupõe uma narrativa que se desenvolve imersa em uma cultura, história comum e memória pessoal. Da mesma forma que em diários ou álbuns de família, as fotos postadas no Instagram funcionam atualmente como a base desse esforço narrativo. É, então, possível definir e confirmar identidades idealizadas, refletidas pelos olhos da mídia e dos outros. Cada usuário utiliza o Instagram como um meio de se fazer conhecido, em imagens que se sucedem em um fluxo continuamente revisado e modificado para corresponder a uma existência virtualmente idealizada (Caldeira, 2016).

Sibilia (2008) compara as postagens na rede com o gênero literário autobiográfico, afirmando que o sujeito que se mostra de forma incansável na web é simultaneamente autor, narrador e personagem. Autor, pois é aquele que cria seus próprios enredos. Narrador, por organizar as suas experiências na primeira pessoa do singular e as apresentar em histórias. No lugar do personagem, se constrói como 
desejar, podendo mudar suas características quando quiser. $O$ Instagram torna-se o palco ideal para exposição de si e a construção de narrativas ao permitir editar e compartilhar fotografias que reforçam a imagem que o usuário constrói para si e para o mundo (Silva, 2012).

Mota e Almeida (2014) ao desenharem o perfil do brasileiro no Instagram assinalam, além das idealizações, que as imagens postadas representam uma homogeneização de identidades, pelo uso de uma linguagem globalizada nos encontros com as culturas externas. Rodrigues e Kublikowski (2014), por sua vez, afirmam que a identidade adulta não possui uma definição concreta e linear, sofrendo influências das transformações contextuais, tecnológicas e sociais, o que permite aos sujeitos construir ativamente trajetórias de vida. No entanto, como observam Pais, Lacerda e Oliveira (2017) apesar da possibilidade de fugir de destinos prováveis, as escolhas biográficas continuam sendo jogadas no tabuleiro das estruturas sociais.

A construção de identidades em aplicativos parece se adequar a padrões normativos de expressão específicos a cada rede. Waterloo, Baumgartner, Peter e Valkenburg (2018) examinaram as normas relativas à expressão das emoções nas redes comparando 0 Facebook, o Twitter, o Instagram, e o WhatsApp e concluem que as expressões de emoções positivas são mais adequadas do que as negativas em todas as plataformas. Carrera (2014) também afirma serem as redes sociais o espaço ideal para a representação da felicidade, especialmente por meio de fotos de rosto que, independentemente de idade e gênero, têm maior probabilidade de receberem curtidas e comentários (Bakhshi, Shamma, \& Gilbert, 2014). Essa valorização dos aspectos positivos da vida é tão forte que os aspectos negativos passam a ser desconsiderados nos momentos das publicações. Manter diferentes contas em diferentes aplicativos é uma estratégia que evita o risco de sanções e rejeição social. A plataforma escolhida no momento permite a expressão apropriada de determinada necessidade.

Os padrões normativos de postagens em diferentes plataformas também apontam para diferenças de gênero, que se manifestam naquelas mais privadas, por propiciarem maior intimidade entre os usuários (Waterloo et al., 2018). Os homens tendem a postar fotos que sinalizam força e habilidades enquanto as mulheres dominam as categorias relativas à aparência pessoal, moda e saúde. Os resultados de Döring, Reif e Poeschl (2016) confirmam que os autorretratos postados no Instagram refletem os estereótipos de gênero. Sibila (2008) acrescenta que frente à exigência de corpos idealizados, as mulheres, mais do que os homens, podem sofrer um impacto na autoestima e alimentarem sentimentos de insegurança e inadequação com o próprio corpo. 
No que tange ao conteúdo das fotos postadas no Instagram, o estudo pioneiro de Yuheng, Manikonda e Kambhampati (2014), define oito categorias de fotos compartilhadas na rede: selfies ou autorretratos, fotos com amigos, atividades em geral, fotos com legenda de humor ou frases de efeito, fotos de alimentos, imagens de aparelhos eletrônicos, questões relacionadas à moda e fotos com animais de estimação, categorias essas que foram utilizadas na análise dos dados da presente pesquisa.

Nesse cenário, a presente investigação teve como foco os adultos jovens, público majoritário no acesso às redes sociais em acordo com o relatório Digital, Social e Mobile de 2016, que indica que no Brasil $49 \%$ da população utiliza as redes sociais. Dentre elas, o Facebook lidera com $31 \%$ e o Instagram ocupa a $5^{a}$ posição, com $15 \%$. A faixa etária que mais utiliza o Facebook é aquela entre 20 a 29 anos, que corresponde a $36 \%$ do total de usuários brasileiros nesta rede específica. Na definição da faixa etária também foi considerada a Cartilha de Políticas Públicas, lançada pelo governo federal em 2013, que subdivide a população entre 15 e 29 anos, em três grupos: jovem adolescente, entre 15 e 17 anos; jovem-jovem, entre 18 e 24 anos; e a categoria de jovem-adulto, entre 25 e 29 anos.

Adotamos a perspectiva sistêmica, que compreende a realidade como construção intersubjetiva, resultante da relação contínua entre homem e demais elementos dos variados sistemas que o cercam, com a linguagem enquanto instrumento que favorece esta construção (Vasconcellos, 2003).

O objetivo geral da pesquisa foi identificar quantitativamente os estilos de uso e compreender, qualitativamente os significados atribuídos por jovens adultos às fotografias de autorretratos postadas no Instagram, da perspectiva da identidade narrativa. Tal objetivo desdobrou-se em objetivos específicos a cada fase do estudo.

$\mathrm{Na}$ fase quantitativa, pretendeu-se: (a) determinar a quantidade de fotografias postadas no Instagram durante um período de 10 dias em 60 perfis, qual o número de curtidas, comentários, hashtags e seguidores de cada sujeito; (b) categorizar as imagens conforme a proposta de Yuheng et al. (2014); (c) investigar diferenças de gênero em relação às categorias postadas; (d) verificar o surgimento de novas categorias de imagens no contexto brasileiro; e (e) destacar os autorretratos e contabilizar o número de curtidas e comentários referentes à cada um.

$\mathrm{Na}$ fase qualitativa, pretendeu-se: (a) compreender os significados que os participantes atribuíram aos autorretratos; (b) compreender os significados que os participantes atribuíram ao número de curtidas, às hashtags e aos comentários postados em relação aos autorretratos, ou à sua ausência; (c) compreender como os colaboradores percebem a percepção do outro às suas postagens. 


\section{Método}

O estudo foi delineado como um estudo Etnográfico online ou Netnografia. Segundo Braga (2013), no modelo etnográfico, o pesquisador, mergulha no universo pesquisado e passa a observar sem ser visto. Surge, então, a observação participante online, centralizada na figura do pesquisador, que utiliza sua rede como principal fonte de dados.

Desenhada por meio do método misto sequencial explanatório, a pesquisa envolveu a combinação entre dados quantitativos e qualitativos para um entendimento mais completo do problema de pesquisa, objetivando a utilização dos elementos qualitativos para explicar os resultados iniciais quantitativos e vice-versa (Creswell \& Clark, 2013). Em ambas as fases a escolha da amostra foi intencional e não aleatória, o que impede a generalização de resultados, mas permite compreender processos de constituição da identidade e significados envolvidos no uso do Instagram por jovens adultos.

\section{Fase quantitativa: colaboradores}

Os 60 colaboradores, 30 homens e 30 mulheres, na fase quantitativa foram selecionados a partir de uma amostragem intencional, por bola de neve (Patton, 2002), que atendiam aos critérios de inclusão e se caracterizaram por: (a) idade entre 25 e 29 anos; (b) possuir perfil na rede social Instagram; (c) ser brasileiro, mas não necessariamente residir no Brasil devido à facilidade de alcance da pesquisa online; (d) postar mais de sete fotografias por semana; (e) ter acesso à Internet.

\section{Fase Quantitativa: procedimento}

Os perfis no Instagram foram selecionados, em um primeiro momento, por indicação de amigos da pesquisadora. Os seguidores dos indicados foram então convidados para a pesquisa até atingirmos 60 perfis. Os dados foram coletados a partir das postagens realizadas pelos colaboradores no intervalo de dez dias escolhidos previamente. O período de coleta, estabelecido com base na pesquisa do Infográfico do Instagram (2015), teve início no dia nove de setembro de 2016, uma sexta-feira, e se encerrou no dia 18 de setembro 2016, em um domingo.

\section{Análise de dados quantitativos}

Com base no estudo de Yuheng et al. (2014), foram contabilizadas e categorizadas as imagens do presente estudo a partir das oito categorias do estudo norte-americano. As fotografias, coletadas na 
etapa quantitativa, foram submetidas à análise documental, por tratar-se de documentos que transmitem uma informação registrada e permitem que sejam gerados conhecimentos e significados (Boccato \& Fujita, 2006). Os resultados foram estatisticamente analisados e descritos por meio de indicadores sintéticos.

\section{Fase Qualitativa: procedimentos}

A seleção de colaboradores para a fase qualitativa se deu em função da frequência de postagens no Instagram alta, média ou baixa, ou seja, por variabilidade máxima, evidenciada na fase quantitativa.

Foram realizadas seis entrevistas semiestruturadas com três homens e três mulheres. Os homens entrevistados foram: a) Miguel, 33 anos, solteiro, superior completo, professor; b) André, 27 anos, solteiro, superior completo, enfermeiro; c) Carlos, 29 anos, solteiro, superior completo, biólogo. As mulheres entrevistadas: a) Laura, 26 anos, solteira, superior incompleto, fotógrafa; b) Beatriz, 31 anos, casada, superior completo, administradora; c) Márcia, 27 anos, solteira, com ensino superior completo, terapeuta ocupacional.

O número final de entrevistas foi estabelecido a partir do critério de saturação (Charmaz, 2005). Em um processo simultâneo de coleta de dados e análise, que se informam mutuamente, somos conduzidos à suficiência interpretativa, segundo a qual a realização de mais entrevistas pouco auxilia na compreensão do fenômeno em foco, à luz dos objetivos.

$O$ roteiro de entrevista semiestruturada girou em torno dos seguintes temas: escolha do Instagram para postagem de fotos, percepção da presença ou ausência de comentários, o significado da postagem de autorretratos, o que gostaria que os outros percebessem nas fotos; se o participante acredita que os outros o vêm da forma pela qual gostaria de ser visto; como o participante acha que é visto a partir das postagens.

As entrevistas qualitativas foram submetidas à análise temática visando identificar e relatar padrões ou temas, em um processo que se constituiu do todo para as partes e das partes para um todo reorganizado de forma a permitir ao pesquisador "ouvir" novas interpretações a partir dos dados (Ezzy, 2002).

\section{Análise e Discussão dos Dados}

Atendendo aos objetivos específicos da fase quantitativa os resultados indicaram que os 60 colaboradores realizaram 769 postagens nos 10 dias estabelecidos. Há uma quantidade maior de fotos postadas por mulheres, 405 imagens, contra 364 imagens postadas por homens. $O$ teste $t$ de Student identificou que não houve 
diferença significativa entre as médias das postagens masculinas e femininas $(t=0,6544 ; p>05)$.

No que se refere ao conteúdo das postagens, foram encontradas no contexto brasileiro sete novas categorias de imagens, além das categorias propostas pelo estudo norte-americano (Yuheng et al., 2014). Foram elas: foto com namorado(a), foto de paisagem, foto com família, foto de objetos em geral, foto de partes do corpo, foto relacionada a questões de luto e montagem de fotografias. Também foram criadas subcategorias de autorretratos, por se tratar do foco do presente trabalho. Oito subcategorias foram criadas: autorretrato rosto, autorretrato meio corpo, autorretrato corpo inteiro, autorretrato costas, autorretrato perfil, autorretrato partes do rosto, autorretrato no espelho e montagem de autorretratos.

O tipo de fotos que surgem com maior frequência para o sexo feminino corresponde aos autorretratos, $43 \%$, seguido por fotos com amigos, com $12 \%$. O autorretrato também domina as postagens masculinas, com um total de $44 \%$, seguido por fotos com amigos, com $16 \%$, resultado que reitera, em nossa amostra, que não há diferenças de gênero em relação à postagem de autorretratos No tocante aos autorretratos postados por homens e mulheres, foi possível constatar que 0 autorretrato predominante nos sexos feminino e masculino é o autorretrato de rosto com $47 \%$ para os homens e $43 \%$ para as mulheres. Em segundo lugar, para os homens, surgem os autorretratos meio corpo, com $22 \%$ de postagens. Já para as mulheres, o autorretrato corpo inteiro, vem em segundo lugar, com 16\%. Neste tópico, existem indicativos de diferenças de gênero em função das partes do corpo valorizadas para homens e mulheres.

É possível criar a hipótese de que os homens preferem exibir, em sua maioria, metade do corpo para valorizar os troncos e braços que representam aspectos da virilidade masculina, da força e que são foco de aperfeiçoamento em atividades físicas. Já as mulheres, quando postam fotos de corpo inteiro, tendem a buscar a harmonia do corpo como um todo, e valorizam as pernas - e glúteos em alguns momentos - em detrimento das outras partes do corpo, símbolos de beleza em nosso país e bastante trabalhadas em atividades físicas, em detrimento dos bíceps, por exemplo, mais valorizado pelos homens (Döring et al., 2016).

Foram contabilizados um total de 2668 hashtags, sendo 1403 para o grupo masculino e 1265 para o grupo feminino, o que representa $53 \%$ para os homens e $47 \%$ para as mulheres. A partir da alimentação do programa Excel com cada hashtag utilizada pelos participantes, aquelas que obtiveram maior frequência foram as seguintes: \#boanoite (62); \#bomdia (35); \#sp (25); \#141 (23); \#lulabarreto (22); \#brasil (21); \#boa-tarde (19); \#trip (17) e \#saopaulo (17); \#love (14), \#deboa (14) e \#amor (14); 
\#beardedman (13); \#me (11) e \#goodvibes (11); \#selfie (10) e \#fitlife (10).

Foi possível perceber a elevada a quantidade de hashtags ligadas à desejos de bom dia/boa tarde/boa noite; também aparecem hashtags ligadas às viagens ou à localidade na qual os colaboradores residem. É interessante notar também hashtags que remontam a sentimentos, à aparência ou ao estilo de vida do participante, levando-nos a refletir que as hashtags são comumente utilizadas para expressar sentimentos, projetos, e ideias, mostrando-se como uma fonte rica para compreender os significados das postagens no Instagram.

Hashtags ligadas à boas energias como \#goodvibes e \#deboa podem estar relacionadas a um caráter de leveza que é imprimido às postagens no Instagram, no qual as experiências são retratadas de forma positiva e tranquila. Aquelas que envolvem 0 amor são bastante comentadas pelos usuários do aplicativo, outro ideal de felicidade da sociedade atual valorizado nas redes sociais. Cabe destacar as hashtags ligadas ao próprio sujeito como \#me e \#selfie que denotam um caráter de exibicionismo que envolve o aplicativo. Por fim, a hashtag \#fitlife que corresponde ao estilo de vida saudável apregoado pela sociedade como ideal de beleza e saúde, que é refletido no aplicativo através de imagens que envolvam a exibição de corpos e exercícios físicos. Assim, observamos nas hashtags significados positivos em acordo com a literatura (Caldeira, 2016; Waterloo et al., 2018)

Dentre todas as categorias presentes no estudo foi possível constatar que o autorretrato rosto foi a categoria que recebeu mais curtidas no grupo pesquisado, seguido por autorretrato perfil e fotos com amigos. Isso aponta para uma relação entre curtida e postagem, uma vez que o autorretrato rosto é a categoria mais postada por ambos os sexos e também a que atrai mais curtidas, levando-nos a refletir que o retorno das curtidas influencia na continuidade das postagens de determinado tipo (Bakhshi et al., 2014).

\section{Significados que permeiam os autorretratos na análise temática da fase qualitativa}

A interpretação dos significados a partir das entrevistas semiestruturadas foi realizada em torno de categorias que se constituíram no processo de análise: diferencial do Instagram; repercussão das postagens; significado dos autorretratos; mensagem das publicações; postagens e perfis que atraem sua atenção; e postagens suas que mais repercutem e seus seguidores.

À categoria temática "Diferencial do Instagram" são atribuídos os significados de uma rede intimista, tecida com vínculos fortes, que permite privacidade e liberdade de expressão e exposição, e que pode se tornar um diário on-line. 
Sobre a escolha do Instagram, os colaboradores elencaram os principais motivos para a criação de um perfil no aplicativo e compararam-no com as demais redes sociais. Por se tratar de uma rede voltada exclusivamente para postagens de imagens (fotografias e vídeos), favorecer o controle de seus seguidores e também a quem o conteúdo compartilhado será direcionado, o Instagram é descrito pelos participantes como um espaço no qual são garantidas a privacidade e liberdade de expressão. $O$ aplicativo oferece também a possibilidade de tornar o perfil privado, no qual só quem pode seguir o usuário são as pessoas que ele aceitar, sem a necessidade de seguir de volta. Descrito como uma rede intimista, favorece as postagens de autorretratos e com pessoas próximas (amigos, familiares e namorados), como encontrado na análise quantitativa.

As principais comparações do Instagram foram feitas com a rede social Facebook. Os colaboradores concordaram que seus perfis no Facebook englobam vários tipos de públicos: dos mais próximos como família nuclear e amigos, a colegas de trabalho, familiares distantes e conhecidos. No Instagram, o círculo de seguidores se torna mais restrito, voltado para os vínculos mais fortes, e isso influencia diretamente no comportamento dos entrevistados nesta rede, que passam a sentir-se mais à vontade para se expor, em consonância com os resultados de Waterloo et al. (2018): "[...] no Instagram eu não tenho obrigação de ser tão contido como no Facebook. O Instagram é uma coisa mais livre para mim". (Miguel)

A temática da privacidade surge como fator primordial para a preferência pelo aplicativo no momento de compartilhar suas imagens. Laura e Márcia abordam uma nova função para o Instagram: um diário (Caldeira, 2016). Se no passado o diário era mantido em total sigilo, atualmente, ele migra para o cenário online e os sentimentos e pensamentos passam a ser divididos com aqueles que são devidamente autorizados à leitura: "É como se fosse um diariozinho meu sabe, é interessante para mim olhar depois para eu mesma ficar refletindo comigo". (Márcia)

Também foi citada a preferência pelo Instagram, que ao contrário do Facebook, exibe em sua linha do tempo todas as fotografias que foram postadas, o que faz do aplicativo um palco ideal para exposição de si (Silva, 2012).

À categoria temática "Repercussão das Postagens" é atribuído o significado de interconstituição de identidades narrativas. Para avaliar as postagens no Instagram, são disponibilizadas duas formas de interação: as curtidas e os comentários. Ao serem questionados sobre a presença ou ausência de comentários em suas postagens, todos os entrevistados relataram que esta prática é pouco comum no aplicativo e elegeram a função curtir como um balizador para identificar se suas postagens estão agradando ao público ou não, como ressalta Beatriz: 
"Já aconteceu de algumas coisas que eu postei não ter tanta curtida assim, eu até sei quando não vão curtir tanto a minha foto, mas isso não tem diferença para mim. Não vou dizer que não reparo, mas eu não repenso minhas postagens por isso, eu não mudo o que postei, não excluo, eu deixo lá. Eu já percebi que se postar fotos com textos muito longos o povo não lê, não se interessa, mais se forem coisas curtas e bem escritas".

Nesse tópico, surgiram contradições: ainda que os entrevistados afirmem que não se importam tanto com os comentários, em vários momentos se referiam à opinião do público como fator que influenciava suas ações. Aqui começam a surgir pistas sobre a construção relacional da identidade (Gergen, 1992). Há um limite no número de postagens estabelecido pela ética na rede. O overposting assume então um sentido negativo: "[...] aí eu penso no meu leitor na hora de publicar uma fotografia, eu nunca publico uma fotografia sem uma razão específica". (Miguel)

Miguel traz também em sua fala um elemento voltado para a abordagem narrativa, quando afirma pensar em seu leitor ao publicar uma imagem, com intuito de impressioná-lo. As imagens, portanto, revelam a história que o autor deseja contar, em acordo com Sibilia (2008), quando associa as postagens online ao gênero literário autobiográfico. Isto mostra que, ainda que todos comentem a importância de realizar postagens que satisfaçam a si mesmos e que o foco não seja a aprovação social, é possível perceber o papel do outro como forte componente que influencia a ação de postar fotos. Mesmo quando esse outro não se manifesta diretamente, sua opinião imaginada acaba por influenciar o comportamento dos colaboradores (Waterloo et al., 2018).

A categoria temática "Significados dos Autorretratos" evidencia a necessidade de mostrar o melhor do não tão perfeito eu. Por se tratar de um aplicativo voltado para a exposição de imagens, com relatos dos participantes acerca da privacidade e a sensação de liberdade para exporem a si próprios, o Instagram se torna o local ideal para o compartilhamento de autorretratos, nos quais os sujeitos entrelaçam suas expectativas com as do público e ambas se confundem no resultado final (Bakhshi et al., 2014). Para tanto, os colaboradores lançam mão dos filtros que alteram a qualidade da fotografia, tiram várias fotografias até eleger uma a ser postada, estabelecem um critério que evite postagens repetitivas, com intuito de mostrar as melhores versões de si mesmos (Caldeira, 2016).

As entrevistas resultaram na unanimidade de preferência por este estilo de fotografia, voltado para a valorização da aparência. Porém, neste tópico surgiram algumas diferenças entre os entrevistados que podem estar atreladas às diferenças de gênero, não visíveis na 
análise quantitativa. Enquanto os homens relataram que suas postagens de autorretratos estão ligadas mais diretamente à vaidade, as mulheres levantaram debates acerca da autoestima e dificuldades de expor o próprio corpo por não se encaixar em um padrão rígido de beleza: "[...] é o meu estilo de foto preferido (autorretrato). [...] A gente melhora aparentemente aí a gente quer se expor mais, quer postar um pouco mais, a gente fica mais bonito, a gente se sente melhor né com o emagrecimento e aí a gente acaba postando um pouco mais" (André). "Eu prefiro bater foto séria, séria não, mas sem sorrir. Às vezes eu acho que fico meio bochechuda, aí eu tenho a preferência de bater com o sorriso sério, fica mais bonito para postar". (Márcia)

As diferenças nas falas femininas e masculinas podem estar relacionadas ao padrão de beleza contemporâneo, muito mais agressivo às mulheres do que aos homens. Com isso, as mulheres podem sofrer um impacto na autoestima e alimentarem sentimentos de vergonha e insegurança com o próprio corpo. Estes sentimentos passam a se refletir nas fotografias, que ao invés de corpos inteiros, exibem autorretratos de rosto (Döring et al., 2016; Sibila, 2008).

À categoria temática "Mensagens das Publicações" é atribuído o significado da felicidade, com o interdito de sentimentos negativos na rede. Surgiram novamente diferenças nas respostas de mulheres e homens. As mulheres relatam como principal mensagem ao público a expressão de seus sentimentos, sejam eles positivos ou negativos, voltados para o empoderamento e amor próprio. Os homens, por outro lado, gostariam de ressaltar sentimentos positivos para seu público: de felicidade, beleza, perfeição, sucesso profissional, com ressalvas em postar sentimentos negativos (Carrera, 2014). Na fala de André, isso se torna claro, evidenciando a pressão nas redes sociais como espaço de exposição de alegrias e conquistas: "Eu acredito que a gente tem que passar o melhor da gente para as pessoas e eu me considero uma pessoa totalmente feliz, realizada profissionalmente, totalmente resolvida e eu acredito que é dessa forma que temos que ser para construir um mundo melhor e eu gosto de passar essa mensagem de felicidade para as pessoas independente de um dia ruim que eu estou tendo".

As colaboradoras afirmam que se utilizam de textos para influenciar outras mulheres no resgate da autoestima e para tentar expressar seus sentimentos e momentos de tristeza. Os sentimentos negativos ficam subentendidos aos seguidores e é comemorado quando outras pessoas percebem esse estado de humor. Ou seja, há uma tentativa de burlar o ideal de felicidade que domina as redes sociais, mas esta tentativa se expressa de forma cautelosa, sem fugir completamente do domínio da felicidade, pois as transgressões podem ter por consequência a falta de curtidas, o não reconhecimento. 
"Penso muito nesse empoderamento feminino, gostaria de vêlas se inspirar e perceber que realmente não importam esses padrões normativos e sim você se achar linda da forma que você é". (Laura)

Ao final da análise, retornamos aos colaboradores e levantamos duas questões: o que eles curtem e quem seguem, e a contrapartida: que tipos de fotos suas eles acreditam atrair mais curtidas e quem são seus seguidores. Este tópico reúne, após todos os questionamentos, o olhar individual de cada colaborador, bem como as expectativas e crenças que possuem acerca do olhar externo, que se traduziram nos significados que apontam para o bom e o belo.

Foi unanimidade entre os colaboradores a atração por fotos que envolvam viagens, paisagens e praias. Isto também está ligado ao ideal de felicidade, no qual viagens e praias são símbolos de alegria e são almejados enquanto conquista pela maioria das pessoas.

"O que mais atrai a minha atenção é quando a pessoa demonstra que está curtindo a vida como: viajar, seus hobbys, afazeres do dia a dia. É algo que me encanta: fotos de praia e viagens que eu adoro. [...] (André).

Foi possível notar uma correlação entre aquilo que os seis colaboradores curtem e seguem, com as postagens que eles acreditam atrair a atenção de seus seguidores e quem são eles. Os entrevistados trouxeram a questão estética como fator que exerce atração por parte deles e de seus públicos, como postagens de antes e depois de um processo de emagrecimento, por exemplo.

A valorização da aparência surge, portanto, como elemento dominante na fala dos entrevistados. O belo é mostrado e seguido simultaneamente, evidenciando ser o Instagram uma rede social que preza a beleza e por ser mais reservada, é onde o sujeito se sente mais à vontade para se expor, contanto que não fuja ao padrão estético apregoado.

As mulheres, que nos tópicos anteriores citaram timidez em expor seus corpos, revelaram consumir os padrões de beleza através das blogueiras, youtubers, vídeos de maquiagem. Isso pode servir como um reforço aos padrões de beleza e intimidá-las quanto à própria exposição por não conseguirem atingir estes padrões.

Quanto aos seguidores, todos os colaboradores declararam seguir e serem seguidos por pessoas de um círculo social próximo como amigos e alguns familiares, reforçando o caráter intimista do aplicativo. 


\section{Considerações Finais}

Em nossa análise quantitativa preliminar não foram encontradas diferenças no estilo de uso do Instagram por homens e mulheres. $O$ autorretrato, semelhante ao estudo americano de Yuheng et al. (2014), foi o tipo de fotografia mais postada pelo grupo. 0 autorretrato de rosto dominou as postagens e revelou-se como importante fonte de significados, envolvendo desde a valorização da aparência a mensagens de empoderamento e reforço da autoestima. As hashtags também surgiram de forma expressiva nas postagens e estavam atreladas a narração do cotidiano de uma forma positiva e alegre. Assim, a fase quantitativa, voltada para a análise das postagens nos ofereceu o mapa dos estilos de uso do Instagram, além de fornecer as informações necessárias para selecionar os participantes para a fase qualitativa.

Por sua vez, e em acordo com Creswell e Clarck (2013), a associação entre informações quantitativas e qualitativas contribuiu para uma compreensão mais ampla da questão em estudo. As narrativas dos colaboradores movimentaram o mapa obtido e, ao transformarem as fotos em filmes, possibilitaram abordar o processo de constituição de identidades narrativas imagéticas no Instagram.

Em relação aos significados atribuídos às postagens, encontramos a noção de privacidade, com a possibilidade de gerenciar com mais facilidade o conteúdo publicado e a quem ele se destinará, tornando o aplicativo mais intimista e reservado. Nesse sentido, os âmbitos público e privado nas redes sociais aparecem delimitados, mas com fronteiras flexíveis e ampliadas. As fotos no Instagram também são compreendidas como memória, um diário, aberto para aqueles que fazem parte do âmbito privado de experiência desses jovens, o que para alguns colaboradores, exclui os familiares que poderiam cercear essa liberdade de expressão.

As curtidas e comentários recebidos foram compreendidos de forma contraditória: apesar dos colaboradores afirmarem que não se baseavam nestes elementos para realizarem suas postagens, a opinião do público surgiu como fator importante em suas falas, especialmente pelo controle da quantidade de fotos que deveriam ser postadas. As mensagens a partir das publicações se mostraram em sua maioria com um caráter positivo, com objetivo de expressar felicidade e sucesso.

Ao longo da fase qualitativa, surgiram diferenças entre os entrevistados homens e mulheres. Enquanto o primeiro grupo demonstrava maior inclinação à exibição de si e de aspectos positivos, as mulheres traziam elementos ligados aos sentimentos e desejo de que seus seguidores pudessem também captar seus momentos tristes, além de demonstrarem inseguranças quanto ao 
próprio corpo, o que pode ser reflexo do padrão de beleza mais agressivo com as mulheres.

Foi possível perceber que há um domínio da cultura de bem-estar e prazer, com postagens em sua maioria reforçando elementos de alegria, com sentimento de tristeza mostrado apenas nas entrelinhas, através de uma narrativa imagética editada, de forma a atender aos ideais sociais de beleza e felicidade, com divulgação limitada a um círculo de seguidores considerados mais próximos e íntimos.

Assim, os significados que os colaboradores atribuem às fotografias postadas na rede se constituem na confluência de suas experiências cotidianas, filtradas e expostas dentro dos padrões esperados que permeiam o tecido social e a identidade que se expõe pode ser considerada narrativa, ao configurar e reconfigurar a vida por meio das histórias contadas, que além de fazerem sentido para os seus protagonistas, são configuradas e reconfiguradas pelos significados que os outros lhe atribuem.

O presente estudo apresenta limitações, em primeiro lugar pela escolha intencional das amostras quantitativa e qualitativa e o contexto cultural no qual se desenrolou, 0 que impede generalizações. Por outro lado, a política de privacidade do Instagram exige apenas em seu perfil público o nome da pessoa, o que impediu - acesso a maiores informações sobre a identificação dos participantes na fase quantitativa. Também o foco da pesquisa mantido no Instagram deixou de analisar as fotos postadas em outras redes, o que, em acordo com Waterloo et al. (2018), poderia nos conduzir a outras considerações.

Apesar das limitações a pesquisa atingiu os objetivos propostos em resultados que parecem ignorar fronteiras, ao apresentarem-se em consonância com pesquisas realizadas em outros contextos, exceto por mais categorias de imagens encontradas no contexto brasileiro, questão que exige ser melhor investigada. Estaríamos frente a uma homogeneização de estilos de uso do aplicativo e de identidades conforme análise de Mota e Almeida (2014), em seu desenho da identidade brasileira no Instagram?

A presente pesquisa abre horizontes para outros estudos a partir de dados quantitativos que permitiram mapear um fenômeno que se expôs de forma pouco sensível às questões de gênero, visíveis de uma perspectiva qualitativa. Porém, pudemos compreender processos a partir dos significados atribuídos pelos participantes aos autorretratos. Tais significados apontam para a constituição relacional de identidades narrativas imagéticas, guiadas pelos ideais de beleza e felicidade, que moldam as formas de expressão possíveis na rede, mesmo frente às tímidas tentativas de subversão ilustradas pelas mulheres.

Alguns significados das postagens no Instagram foram desvelados, porém muitos ainda exigem o esforço e a continuidade de pesquisas 
na área. Esperamos que este estudo possa servir como base para novas reflexões sobre a exposição no cenário online, especialmente em função de padrões ideais que permeiam o contexto cultural e ecoam o fato de que as redes reproduzem significados sedimentados e, por meio de um olhar que vigia e curte, limitam a liberdade imaginada nas jogadas das escolhas biográficas.

\section{Referências}

Bakhshi, S., Shamma, D. A., \& Gilbert, E. (2014). Faces engage us: Photos with faces attract more likes and comments on instagram. In Proceedings of the SIGCHI Conference on Human Factors in Computing Systems (pp. 965-974). New York: ACM.

Boccato, V. R. C., \& Fujita, M. S. L. (2006). Discutindo a análise documental de fotografias: Uma síntese bibliográfica. Cadernos Bad, (2), 85-100. Recuperado de http://www.bad.pt/publicacoes/index.php/cadernos/article/view $/ 794$

Braga, A. (2013). Netnografia: compreendendo o sujeito nas redes sociais. In A. M. Nicolaci-da-Costa, \& D. Romão-Dias (Orgs.), Qualidade faz diferença: métodos qualitativos para a pesquisa em psicologia e áreas afins (pp. 171-197). Rio de Janeiro: Ed. PUC-RIO; São Paulo: Loyola.

Brasil. (2013). Cartilha de Políticas Públicas Para a Juventude. Brasília, DF: Secretaria Nacional de Juventude. Recuperado de http://bibjuventude.ibict.br/jspui/handle/192/54

Caldeira, S. P. (2016). Identities in flux: An analysis to photographic self-representation on Instagram. Observatorio (OBS*), 10(3), 135-158. doi:10.15847/obsOBS10320161031

Carrera, F. (2014). O imperativo da felicidade em sites de Redes sociais: Materialidade como subsídio para o gerenciamento de impressões (quase) sempre positivas. Revista Eptic Online, 16(1), 33-44. Recuperado de https://seer.ufs.br/index.php/eptic/article/view/1857/1639

CETIC. (2017). TIC Domicílios e Usuários: pesquisa sobre o uso das tecnologias de informação e comunicação nos domicílios brasileiros. Recuperado em 20 abril, 2018, de https://cetic.br/media/analises/tic_domicilios_2017_coletiva_de imprensa.pdf

Charmaz, K. (2005). Grounded Theory in the 21st. Century. In N. K. Denzin, \& Y. S. Lincoln (Eds.), The Sage Handbook of Qualitative Research (3a ed., pp. 507-535). Thousand Oaks: Sage. 
Creswell, J. W., \& Clark, V. L. P. (2013). Pesquisa de Métodos Mistos: Série Métodos de Pesquisa (2a ed.). Porto Alegre: Penso Editora.

Döring, N., Reif, A., \& Poeschl, S. (2016). How gender-stereotypical are selfies? A content analysis and comparison with magazine adverts. Computers in Human Behavior, 55, 955-962. doi:10.1016/j.chb.2015.10.001

Ezzy, D. (2002). Qualitative Analysis: Practice and innovation. Londres: Routledge.

Gergen, K. J. (1992). El yo saturado: Dilemas de la identidad en el mundo contemporáneo. Barcelona: Paidós.

Hogan, B., \& Wellman, B. (2014). The relational self-portrait: Selfies meet social networks. In M. Graham, \& W. H. Dutton (Eds.), Society \& the Internet: How networks of information and communication are changing our lives (pp. 53-66). Oxford: Oxford University Press.

Iconosquare. (2015). Instagram 2015 study: Unleash the power of Instagram. Recuperado

https://blog.iconosquare.com/instagram-2015-study-unleashpower-instagram/

Instagram. (2016). Instagram Press. Recuperado de https://www.instagram.com/press/

Mota, C. M. L., Almeida, P. H. (2014). O brasileiro no Instagram: Uma identidade Globalizada. In Martins, M. L, Cabecinhas, R., Macedo, L. \& Macedo (Eds.), Interfaces da Lusofonia (pp. 245256). Braga: Centro de Estudos da Comunicação e Sociedade, Universidade do Minho. Recuperado de http://www.lasics.uminho.pt/ojs/index.php/cecs_ebooks/issue/ view/133/showToc

Pais, J. M., Lacerda, M. P. C. D., \& Oliveira, V. H. N. (2017). Juventudes contemporâneas, cotidiano e inquietações de pesquisadores em Educação-uma entrevista com José Machado Pais. Educar em Revista, (64), 301-313. doi:10.1590/01044060.50119

Patton, M. Q. (2002). Qualitative research \& evaluation methods (3a ed.). Thousand Oaks: Sage.

Ricoeur, P. (1997). Tempo e narrativa III. São Paulo: Papirus.

Rodrigues, C.M., \& Kublikowski, I. (2014). Os pais e a transição do jovem para vida adulta, 45(4), 524-534. Recuperado de http://revistaseletronicas.pucrs.br/ojs/index.php/revistapsico/a rticle/viewFile/16372/1247

Sibilia, P. (2008). O show do eu. Rio de Janeiro: Nova Fronteira.

Silva, P. I. R. (2012, Junho). Dinâmicas comunicacionais na representação da vida cotidiana - Instagram: Um modo de narrar sobre si, fotografar ou de olhar para se ver. Trabalho apresentado no Congresso de Ciências da Comunicação na 
Região Sudeste, Intercom, Sociedade Brasileira de Estudos Interdisciplinares da Comunicação, Ouro Preto, Minas Gerais, $17 . \quad$ Recuperado de http://www.intercom.org.br/papers/regionais/sudeste2012/resu mos/R33-1626-2.pdf

Tozetto, C. (2015, Novembro 9). Com 29 milhões de usuários; Brasil impulsiona crescimento do Instagram (2015). Jornal Estado de São Paulo (Estadão). Recuperado de http://link.estadao.com.br/noticias/empresas,com-29-milhoesde-usuarios-brasil-impulsiona-crescimento-doinstagram, 10000028875

Vasconcellos, M. J. E. (2003). Pensamento sistêmico: O novo paradigma da ciência (4a ed.) Campinas, SP: Papirus Editora.

Waterloo, S. F., Baumgartner, S. E., Peter, J., \& Valkenburg, P. M. (2018). Norms of online expressions of emotion: Comparing Facebook, Twitter, Instagram, and WhatsApp. New Media \& Society, 20(5), 1813-1831. doi:10.1177/1461444817707349

We Are Social. (2016). Relatório Digital, Social e Mobile. Recuperado de http://pt.slideshare.net/wearesocialsg/digital-in-2016/2wearesocialsg_2

Yuheng. H., Manikonda, L., \& Kambhampati, S. (2014). What We Instagram: A first analysis of instagram photo content and user types. In Proceedings of the 8th International Conference on Weblogs and Social Media, ICWSM 2014 (pp. 595-598). Califórnia: The AAAI Press. Recuperado de http://rakaposhi.eas.asu.edu/instagram-icwsm.pdf

\section{Endereço para correspondência \\ Zakiee Castro Mufarrej Hage}

Avenida Alcindo Cacela, 1625, Nazaré, CEP 66040-020, Belém - PA, Brasil

Endereço eletrônico: zakieehage@hotmail.com

Ida Kublikowski

Rua Monte Alegre 984, Perdizes, CEP 05014-901, São Paulo - SP, Brasil

Endereço eletrônico: idakublikowski@pucsp.br

Recebido em: 11/10/2018

Reformulado em: 27/05/2019

Aceito em: 10/06/2019

\section{Notas}

* Doutoranda em Psicologia Clínica (Pontifícia Universidade Católica de São Paulo).

** Doutora em Psicologia Clínica (Pontifícia Universidade Católica de São Paulo).

Financiamento: Conselho Nacional de Desenvolvimento Científico e Tecnológico Brasil (CNPQ)

Este artigo de revista Estudos e Pesquisas em Psicologia é licenciado sob uma Licença Creative Commons Atribuição-Não Comercial 3.0 Não Adaptada. 